\title{
Laminar fluid flow in concentric annular ducts of non-conventional cross-section applying GBI method
}

\author{
Escoamento de fluido laminar em dutos anulares concêntricos de seção transversal não \\ convencional aplicando o método GBI
}

Flujo de fluido laminar en conductos anulares concéntricos de sección transversal no convencional utilizando el método GBI

Received: 12/29/2020 | Reviewed: 12/30/2020 | Accept: 12/31/2020 | Published: 01/04/2021

Valdecir Alves dos Santos Júnior ORCID: https://orcid.org/0000-0003-1953-5059

Universidade Estadual da Paraíba, Brazil

E-mail: asjrvaldecir@servidor.uepb.edu.br

Antonio Gilson Barbosa de Lima ORCID: https://orcid.org/0000-0003-1691-1872 Universidade Federal de Campina Grande, Brazil E-mail: antonio.gilson@ufcg.edu.br

Severino Rodrigues de Farias Neto ORCID: https://orcid.org/0000-0001-9826-2110 Universidade Federal de Campina Grande, Brazil E-mail: Severino.rodrigues@ufcg.edu.br Igor Fernandes Gomes ORCID: https://orcid.org/0000-0003-2474-383X Universidade Federal de Pernambuco, Brazil E-mail: igor.fernandes@ufpe.br

Jonathan da Cunha Teixeira

ORCID: https://orcid.org/0000-0003-4271-1479

Universidade Federal de Pernambuco, Brazil E-mail: jonta.teixeira@gmail.com

\begin{abstract}
Fluid flow in concentric or eccentric annular ducts have been studied for decades due to large application in medical sciences and engineering areas. This paper aims to study fully developed fluid flow in straight ducts of concentric annular geometries (circular with circular core, elliptical with circular core, elliptical with elliptical core, and circular with elliptical core) using the Galerkin-based Integral method (GBI method). The choice of method was due to the fact that in the literature it is not applied in ducts of cross-sections of the annular shape with variations between circular and elliptical. Results of different hydrodynamics parameters such as velocity distribution, Hagenbach factor, Poiseuille number, and hydrodynamic entrance length, are presented and analyzed. In different cases, the predicted hydrodynamic parameters are compared with results reported in the literature and a good concordance was obtained.
\end{abstract}

Keywords: Fully developed flow; Non-circular duct; Galerkin-based integral method; Circular; Elliptical.

\section{Resumo}

O fluxo de fluidos em dutos anulares concêntricos ou excêntricos tem sido estudado há décadas devido à grande aplicação nas ciências médicas e nas áreas de engenharia. Este trabalho tem como objetivo estudar o escoamento de fluidos completamente desenvolvido em dutos retos de geometrias anulares concêntricas (circular com núcleo circular, elíptico com núcleo elíptico, elíptico com núcleo elíptico e circular com núcleo elíptico) usando o método Integral baseado em Galerkin (método GBI). A escolha do método se deu pelo fato de que na literatura não se encontra aplicado em dutos de seções transversais da forma anulares com variações entre circular e elíptica. Resultados de diferentes parâmetros hidrodinâmicos, como distribuição de velocidade, fator de Hagenbach, número de Poiseuille e comprimento de entrada hidrodinâmica, são apresentados e analisados, tanto em tabelas como em forma de gráficos. Em diferentes casos, os parâmetros hidrodinâmicos previstos são comparados com os resultados relatados na literatura e uma boa concordância foi obtida.

Palavras-chave: Fluxo completamente desenvolvido; Duto não circular; Método integral baseado em Galerkin; Circular; Elíptico. 


\begin{abstract}
Resumen
El flujo de fluidos en conductos anulares concéntricos o excéntricos se ha estudiado durante décadas debido a su amplia aplicación en las ciencias médicas y la ingeniería. Este trabajo tiene como objetivo estudiar el flujo de fluido desarrollado íntegramente en conductos rectos de geometrías anulares concéntricas (circular con núcleo circular, elíptica con núcleo elíptico, elíptica con núcleo elíptico y circular con núcleo elíptico) utilizando el método Integral basado en Galerkin (método GBI). La elección del método se debió a que en la literatura no se aplica en conductos de sección transversal de forma anular con variaciones entre circulares y elípticas. Los resultados de diferentes parámetros hidrodinámicos, como la distribución de velocidades, el factor de Hagenbach, el número de Poiseuille y la longitud de entrada hidrodinámica, se presentan y analizan, tanto en tablas como en forma de gráficos. En diferentes casos, los parámetros hidrodinámicos predichos se comparan con los resultados reportados en la literatura y se obtuvo una buena concordancia.
\end{abstract}

Palabras clave: Flujo completamente desarrollado; Conducto no circular; Método integral basado en Galerkin; Circular; Elíptico.

\title{
1. Introduction
}

Researches related to internal fluid flow in curved and straight ducts is crucial at different fields of medical sciences and engineering. For decades, the studies focus in incompressible and laminar flow in singly ducts with circular, rectangular, elliptical, polygonal, and triangular cross-sections, and many others geometries (Cadé et al., 2010; Manoj et al., 2013; Lasode et al., 2013; Lekner, 2007; Etaig \& Hashem, 2020; Das \& Tahmouresi, 2016; Velusamy \& Garg, 1993), and in doubly-connected ducts (concentric or eccentric) with different configurations (Lundgren et al., 1964; Sparrow \& Lin, 1964; Alegria et al., 2012; McComas, 1967; Shah \& London, 1978; Solanki et al., 1986; Moharana \& Khandekar, 2013; Lee \& Kuo, 1998; Park \& Lee, 2002; Shivakumar, 1993; Ferroudji et al., 2019; Liu, 1974; Sugino, 1962; Heaton et al., 1962; Gulraiz \& Gray, 2020; Escudier et al., 1995; Nouar, et al., 1995; Khalil eta al., 2008; Muzychka \& Yovanovich, 2009; Colmanetti, 2016; Pinto, 2016; Uner et al., 1988; Alves et al., 2014; Lee \& Lee, 2001). Such effort has been given to predict Newtonian fluid flow in ducts with considerable progress.

Several solution techniques have been developed, over the years, to obtain information about hydrodynamic parameters that characterize the flow in ducts with different cross-section geometries.

Alegria et al. (2012), presented an analytical and numerical study for the isothermal flow of Herschel-Bulkley viscoplastic fluid using three duct configurations of elliptical cross-sections: elliptical duct, concentric annular elliptical and circular eccentric. This study aimed to analyze the effect of geometric and rheological parameters of the fluid with pressure drop.

Alves et al. (2014), presented a hybrid analytical-numerical solution for the isothermal hydrodynamic problem of the fully developed laminar flow in circular concentric annular ducts using the Generalized Integral Transform Technique (GITT). In this work, the authors applied a conform transform, together with the GITT and presented results for Poiseuille number, Hagenbach factor, and velocity profiles.

The Galerkin-based integral (GBI) method has well-known applicability in flow analysis in straight ducts with arbitrary geometry (Lee \& Kuo, 1998; Lee \& Lee, 2001; dos Santos Júnior et al., 2020; Santos Júnior, 2018; Haji-Sheikh \& Beck, 1990; Lakshminarayanan \& Haji-Sheik, 1992). However, it can also be used in other engineering areas (Franco et al., 2016; Pessôa et al., 2017; Santos et al., 2015; Santos et al., 2012; Lima et al., 2004; Franco et al., 2019; Franco et al., 2020; Lima et al., 2014).

Dos Santos Júnior et al. (2020), present a theoretical study applied to fully developed internal laminar flow through a corrugated cylindrical duct, using the Galerkin-based integral method. As an application, the authors have used the proposed formulation to predict heavy oil flow at different operating conditions considering temperature-dependent viscosities ranging from 1715 to $13000 \mathrm{cP}$. In this research are reported many fluid dynamics parameters, such as the Fanning friction factor, Reynolds number, shear stress, and pressure gradient. 
Given the real importance, the range of work, the applicability of annular ducts and also the shortage of results in the analysis of fluid flow in ducts with annular elliptical geometry, this work aims to study the fluid dynamic behavior of incompressible and Newtonian fluid in non-conventional geometries using the Galerkin-based Integral Method. Four geometries were used: circular with circular core, elliptical with circular core, elliptical with elliptical core, and circular with elliptical core.

Although the fluid flow theory is well understood very few studies have attempted to predict fluid flow in duct with annular geometry using the GBI method. Thus, it is clear, the innovative contribution of this research: fluid flow in nonconventional and annular geometries not yet fully understood and several physical situations remain unsolved. In essence, this is purely quantitative research, according to Pereira et al. (2018).

\section{Methodology}

For an appropriated mathematical formulation related to fluid flow in ducts, the following assumptions are given:
a) Single-phase and laminar flow;
b) Steady-state flow regime;
c) Hydrodynamically developed flow;
d) Incompressible and Newtonian fluid with constant thermo-physical properties;
e) The cross-section area of the duct is constant along the z-axis;
f) Smooth wall duct (Null roughness);
g) Radial and angular velocity components are everywhere zero;
h) Body force effect is neglected;

\section{The Geometry and base functions}

For mathematical analysis we choose the cylindrical coordinate system $(r, \theta, z)$. The concentric annular geometries to be analyzed will be: circular with core circular and elliptical with core elliptical. For these geometries we will use the following parameterizations:

$$
c_{1}(\theta)= \pm \sqrt{\frac{a_{1}^{2} p_{1}^{2}}{p_{1}^{2} \cos ^{2}(\theta)+a_{1}^{2} \sin ^{2}(\theta)}}
$$

and

$$
c_{2}(\theta)= \pm \sqrt{\frac{a_{2}^{2} p_{2}^{2}}{p_{2}^{2} \cos ^{2}(\theta)+a_{2}^{2} \sin ^{2}(\theta)}}
$$

where $a_{i}$ and $p_{i}$, with $i=1,2$, are the axes of the ellipse, when $a_{i} \neq p_{i}$ and the radius of the circumference when $a_{i}=p_{i}$, with $0 \leq \theta \leq 2 \pi$, as illustrated in Figure 1. This way, it is possible to obtain large varieties of geometries for the duct combining only these parameters. 
Figure 1: Curves $c_{1}(\theta)$ and $c_{2}(\theta)$ with $a_{1}=p_{1}=1, a_{2}=0.5$ and $p_{2}=0.3$.

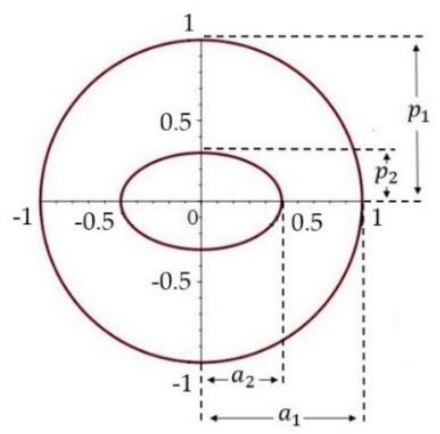

Source: Authors (2020)

Thus, considering the cross-section given by the curves $c_{1}(\theta)$ and $c_{2}(\theta)$, the cross-section area of the duct is given by:

$$
A_{c}=\frac{1}{2}\left[\int_{0}^{2 \pi} c_{1}(\theta)^{2} d \theta-\int_{0}^{2 \pi} c_{2}(\theta)^{2} d \theta\right]
$$

For the perimeter of the cross-section of the duct, it was applied the formal definition of arc length as follows:

$$
P=\int_{0}^{2 \pi} \sqrt{c_{1}(\theta)^{2}+\left(\frac{d}{d \theta} c_{1}(\theta)\right)^{2}}+\int_{0}^{2 \pi} \sqrt{c_{2}(\theta)^{2}+\left(\frac{d}{d \theta} c_{2}(\theta)\right)^{2}}
$$

In this study, it was considered the geometries cited before and shown in Figure 2. The fluid flows in the annular region:

Figure 2: Geometries a) G1-circular with core circular, $\left(a_{1}=p_{1}\right)>\left(a_{2}=p_{2}\right)$; b) G2-elliptic with core circular, $\left(a_{1}>p_{1}\right)>$ $\left(a_{2}=p_{2}\right)$; c) G3-elliptic with core elliptic, $\left(a_{1}>p_{1}\right)>\left(a_{2}>p_{2}\right)$ and d) G4-circular with core elliptic, $\left(a_{1}=p_{1}\right)>\left(a_{2}>\right.$ $\left.p_{2}\right)$.

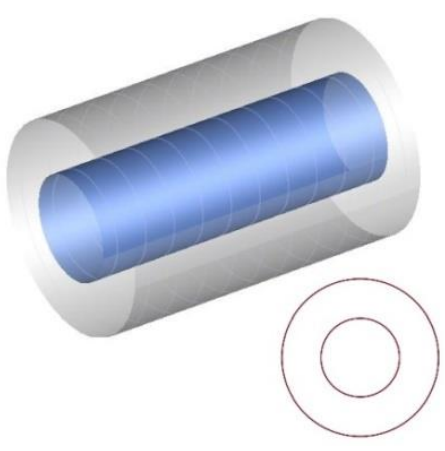

a)

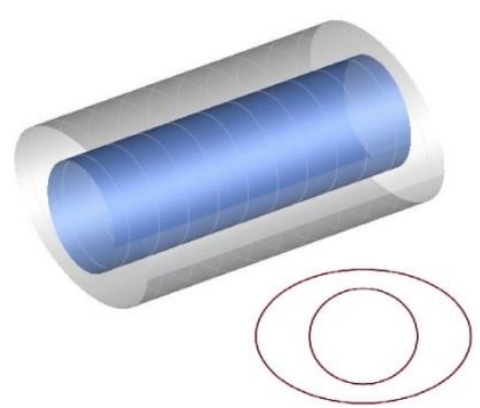

b) 


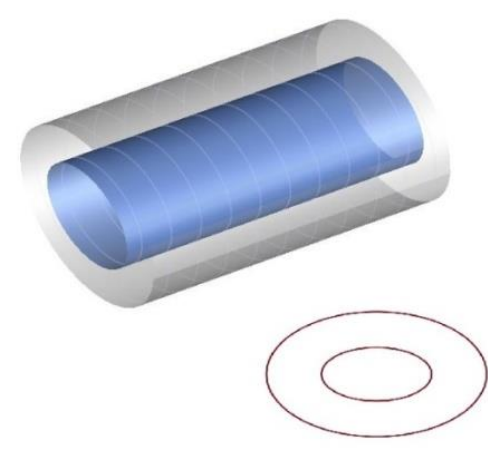

c)

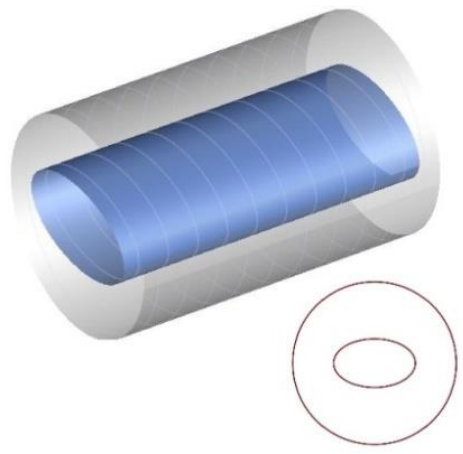

d)

Source: Authors (2020).

Considering the parameterization in polar coordinates, $c_{1}(\theta)$ and $c_{2}(\theta)$, we define the following functions:

$$
g(r, \theta)=\left(c_{1}(\theta)^{2}-r^{2}\right)\left(c_{2}(\theta)^{2}-r^{2}\right), \quad \text { with } 0 \leq \theta \leq 2 \pi
$$

Thus, the set of bases functions will be as follows:

$$
\left\{f_{i}\right\}=\left\{g(r, \theta), g(r, \theta) r, g(r, \theta) \theta, g(r, \theta) r \theta, \ldots, g(r, \theta) r^{n} \theta^{m}\right\}
$$

Putting Equation (5) into equation (6), we can write base functions as follows:

$$
f_{i}(r, \theta)=g(r, \theta) r^{n} \theta^{m} \text { with } n, m=0,1,2, \ldots, N
$$

where the subscript $i$ represents the $i$-th term of the set of base functions in Equation (6).

\section{Linear momentum equation and solution methodology}

Now, considering the hypotheses cited before, the linear momentum equation written in the cylindrical coordinate system, is given as follows:

$$
\frac{\partial^{2} u}{\partial r^{2}}+\frac{1}{r} \frac{\partial u}{\partial r}+\frac{1}{r^{2}} \frac{\partial^{2} u}{\partial \theta^{2}}=\frac{1}{\mu} \frac{d p}{d z}
$$

where, $u(r, \theta)$ is the velocity component along the z-axis and annulled in the boundary $\Gamma(u(r, \theta)=0, \forall z$, no slip condition), $\frac{d p}{d z}$ is the pressure gradient, and $\mu$ is the dynamic velocity of the fluid. Since transversal velocity components are zero so, $\frac{d u}{d z}=0$ (from mass conservation equation), and transversal pressure gradient are zero. Thus, $u(r, \theta)$ does not depend on the axial coordinate $z$, and longitudinal pressure gradient becomes constant. The dimensionless form of Equation (8) for a hydrodynamically fully developed flow, yield:

$$
\frac{\partial^{2} W}{\partial R^{2}}+\frac{1}{R} \frac{\partial W}{\partial R}+\frac{1}{R^{2}} \frac{\partial^{2} W}{\partial \theta^{2}}=-1
$$

with $W=0$ in $\Gamma$. In Equation (9) were considered the following dimensionless parameters:

$$
R=\frac{r}{L}
$$




$$
W(R, \theta)=-\frac{u(R, \theta)}{\frac{L^{2}}{\mu} \frac{d p}{d z}}
$$

where $L$ is the characteristic length.

Since the mean velocity of the fluid is given by:

$$
u_{m}=\frac{1}{A_{c}} \int_{A_{c}} u d A_{c}
$$

the normalized dimensionless mean velocity can be written as follows:

$$
U=\frac{u}{u_{m}}=\frac{W}{W_{m}}
$$

where $W_{m}$ is the dimensionless mean velocity of the fluid.

In this research, the solution of the momentum equation was obtained by using Galerkin-based integral method (GBI method). This method isn't new, but never have been applied to predict fluid flow in ducts with non-conventional cross-section ducts.

By the GBI method, the solution is approximated as a linear combination of a set of base functions. Thus, for the Equation (9), we can written:

$$
W=\sum_{i=1}^{n} d_{i} f_{i}(R, \theta)
$$

The functions $f_{1}, f_{2}, \ldots, f_{n}$ are linearly independent functions and satisfy the same homogeneous boundary conditions of $W$.

Applying the GBI method in Equation (9) and replacing W as in the Equation (14), we obtain the following matrix system:

$$
A D=B
$$

where

$$
a_{i j}=\frac{1}{A_{c}} \int_{A_{c}}\left(\frac{\partial^{2} f_{j}}{\partial R^{2}}+\frac{1}{R} \frac{\partial f_{j}}{\partial R}+\frac{1}{R^{2}} \frac{\partial^{2} f_{j}}{\partial \theta^{2}}\right) f_{i} d A_{c}=\frac{1}{\mathrm{~A}_{c}} \int_{A_{c}} f_{i} \nabla^{2} f_{j} d A_{c}
$$

and

$$
b_{i}=-\frac{1}{A_{c}} \int_{A_{c}} f_{i} d A_{c}
$$

Since that

$$
D=A^{-1} B
$$

we obtain the coefficients $d_{1}, d_{2}, \ldots, d_{n}$ of Equation (14).

The dimensionless mean velocity is given by:

$$
W_{m}=\frac{1}{A_{c}} \int_{A_{c}} W d A_{c}=\sum_{j=1}^{n} d_{j} \frac{1}{A_{c}} \int_{A_{c}} f_{j} d A_{c}=-\sum_{j=1}^{n} d_{j} b_{j}
$$


The Fanning friction factor, $f$, is defined by:

$$
f=\frac{\tau_{w}}{\rho \frac{u_{m}^{2}}{2}}
$$

where $\tau_{w}=-\frac{d_{h}}{4} \frac{d p}{d z}$ represents the shear stress with $d_{h}=\frac{4 A_{c}}{P}$ the hydraulic diameter.

The Reynolds number is defined as:

$$
R e=\frac{\rho d_{h} u_{m}}{\mu}
$$

A parameter of great interest in fluid mechanics is the Poiseuille number. It is defined as the product of the Reynolds number and the friction factor, as follows:

$$
f R e=\frac{D_{h}^{2}}{2 W_{m}}
$$

with, $D_{h}=\frac{d_{h}}{L}$ is the dimensionless hydraulic diameter.

The number of increments in the pressure drop or Hagenbach factor, K ( $\infty)$, according to reference Shah \& London (1978), is defined as:

$$
K(\infty)=\frac{2}{A_{c}} \int_{A_{c}}\left(U^{3}-U^{2}\right) d A_{c}
$$

or,

$$
K(\infty)=2\left[K_{e}(\infty)-K_{d}(\infty)\right]
$$

where $K_{e}(\infty)$ and $K_{d}(\infty)$, are respectively the kinetic energy correction factor and the momentum flux correction factor, given by:

$$
K_{e}(\infty)=\frac{1}{A_{c}} \int_{A_{c}} U^{3} d A_{c}
$$

and

$$
K_{d}(\infty)=\frac{1}{A_{c}} \int_{A_{c}} U^{2} d A_{c}
$$

The dimensionless hydro-dynamic entry length, $L_{h z}^{+}$, according to Shah \& London (1978), is given by:

$$
L_{h z}^{+}=\frac{U_{\max }^{3}-1-K(\infty)}{4 f R e}
$$

where $U_{\max }=\frac{W_{\max }}{W_{m}}$ is the maximum normalized dimensionless velocity, $W_{\max }$ is the maximum dimensionless velocity.

\section{Numerical Computation}

For obtain the numerical results, a computational code in the software Maple Student Edition was developed. Following, the flowchart shows the calculation procedure using the GBI method: 
Figure 3: Flowchart of the solution procedure.

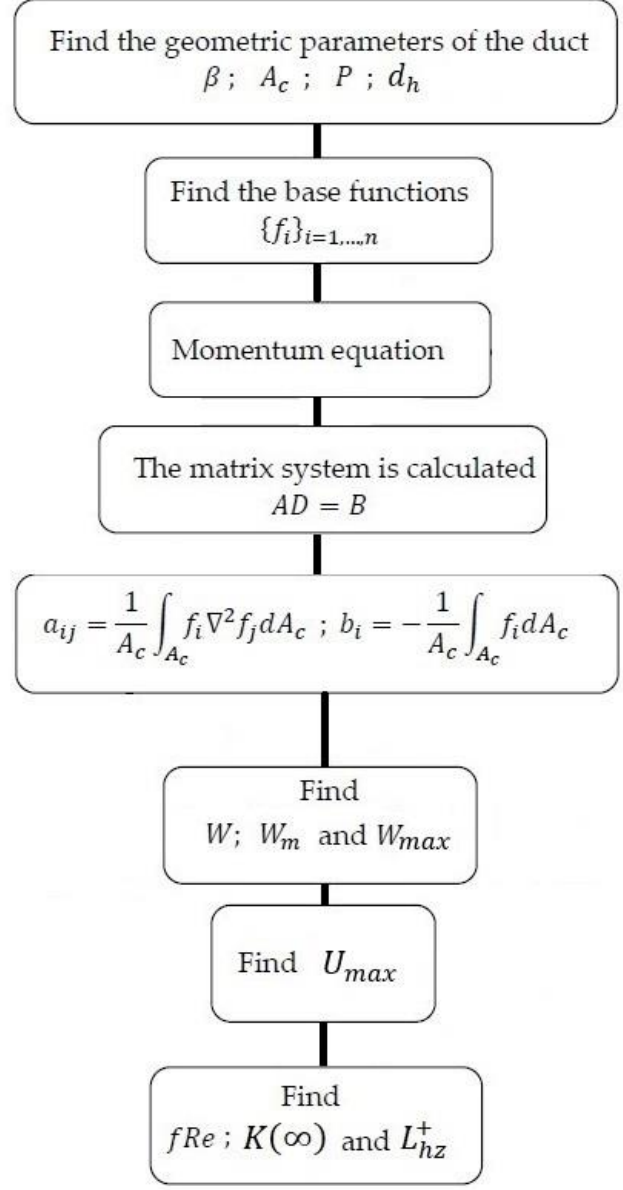

Source: Authors (2020).

\section{Results and Discussion}

In this section, we present the numerical results obtained for different hydrodynamic parameters (Poiseuille number, Hagenbach factor and dimensionless entry length) obtained for different aspects ratio of the geometries presented in Figure 2. In the simulations, we consider the characteristic length $L=1$ corresponding to the radius of the outer circumference or half of the major axis of the outer ellipse.

G1 geometry

For G1 geometry, (Figure 2a), consider the aspect ratio given by $\beta=\frac{p_{2}}{p_{1}}$, with $a_{1}=p_{1}=1$ and $a_{2}=p_{2}$, as illustrated in Figure 4a. Figure 4b illustrates the velocity field of the fluid inside the duct over the entire cross-section. It can be verified that velocity is zero at the wall and increasing towards the central region of the annular. This behavior occurs because of the noslip condition established in the simulations. The friction effect is transmitted for all layers of fluid that are adjacent (formation of the hydrodynamic boundary layer). 
Figure 4: a) Geometrical profile, and b) Normalized dimensionless velocity profile of the G1 geometry ( $\left.1, a_{2}=p_{2}=0.5\right)$.

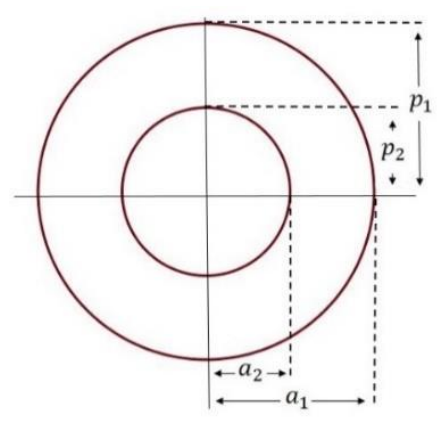

a)

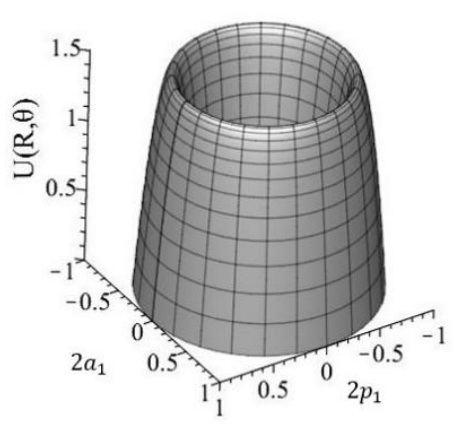

b)

Source: Authors (2020).

In Table 1, we present the values of the hydrodynamics parameters obtained of the simulations. We take the aspect ratio $\beta=\frac{p_{2}}{p_{1}}$ ranging from 0.01 to 0.9 . From the analysis of this table, we can see that increased values of the aspect ratio $\beta$, the Poiseuille number has increased. In contrast, all others parameters have been reduced. When $\beta \rightarrow 0$, we have the parameterization and the value of the Poiseuille number, $f R e=16$, of the circular duct. On the other hand, as the $\beta>1$, the system becomes two parallel flat plates with almost null thickness. Furthermore, in Table 1 velocities peaks are observed clearly. 
Research, Society and Development, v. 10, n. 1, e10710111547, 2021

(CC BY 4.0) | ISSN 2525-3409 | DOI: http://dx.doi.org/10.33448/rsd-v10i1.11547

Table 1. Several hydrodynamics parameters obtained for G1 geometry.

\begin{tabular}{|c|c|c|c|c|c|c|}
\hline$\beta=\frac{p_{2}}{p_{1}}$ & $f R e$ & $W_{m}$ & $U_{\max }$ & $K(\infty)$ & $L_{h z}^{+}$ & $D_{h}$ \\
\hline 0.01 & 22.3431 & 0.0839 & 1.6325 & 0.8792 & 0.008417 & 1.980 \\
\hline 0.05 & 22.5540 & 0.0800 & 1.6014 & 0.8567 & 0.007844 & 1.900 \\
\hline 0.10 & 22.5777 & 0.0717 & 1.5590 & 0.8208 & 0.006752 & 1.800 \\
\hline 0.15 & 22.8479 & 0.0632 & 1.5400 & 0.7794 & 0.006482 & 1.700 \\
\hline 0.20 & 23.1033 & 0.0554 & 1.5312 & 0.7575 & 0.006352 & 1.600 \\
\hline 0.25 & 23.3058 & 0.0482 & 1.5251 & 0.7397 & 0.006289 & 1.500 \\
\hline 0.30 & 23.4623 & 0.0417 & 1.5203 & 0.7275 & 0.006220 & 1.400 \\
\hline 0.35 & 23.5835 & 0.0358 & 1.5162 & 0.7178 & 0.006160 & 1.300 \\
\hline 0.40 & 23.6784 & 0.0304 & 1.5128 & 0.7109 & 0.006100 & 1.200 \\
\hline 0.45 & 23.7532 & 0.0254 & 1.5099 & 0.7054 & 0.006048 & 1.100 \\
\hline 0.50 & 23.8127 & 0.0209 & 1.5076 & 0.7009 & 0.006006 & 1.000 \\
\hline 0.55 & 23.8596 & 0.0169 & 1.5057 & 0.6975 & 0.005970 & 0.900 \\
\hline 0.60 & 23.8970 & 0.0133 & 1.5042 & 0.6944 & 0.005946 & 0.800 \\
\hline 0.65 & 23.9264 & 0.0102 & 1.5030 & 0.6886 & 0.005962 & 0.700 \\
\hline 0.70 & 23.9494 & 0.0075 & 1.5020 & 0.6865 & 0.005945 & 0.600 \\
\hline 0.75 & 23.9670 & 0.0052 & 1.5013 & 0.6861 & 0.006027 & 0.500 \\
\hline 0.80 & 23.9801 & 0.0033 & 1.5007 & 0.6856 & 0.005807 & 0.400 \\
\hline 0.85 & 23.9896 & 0.0018 & 1.5003 & 0.6847 & 0.005849 & 0.300 \\
\hline 0.90 & 23.9950 & 0.0008 & 1.5001 & 0.6741 & 0.005981 & 0.200 \\
\hline
\end{tabular}

Source: Authors (2020).

To assure the accuracy of the values presented in Table 1, the number of base functions ranged from $N=5$ to $N=15$. When the aspect ratio tends to be $\beta=1$, more base functions are needed to better approximates the values predicted by simulations with that reported in the literature. The proposed model and the solution procedure were validated with previous works reported in the literature. Figure 5-7 show these results. From the analysis of there figures, we can see that on excellent agreement was obtained, except for small number of the aspect ratio, where some discrepancy are seen. 
Research, Society and Development, v. 10, n. 1, e10710111547, 2021

(CC BY 4.0) | ISSN 2525-3409 | DOI: http://dx.doi.org/10.33448/rsd-v10i1.11547

Figure 5: Poiseuille number for different aspect ratios compared to the literature data (G1 geometry).

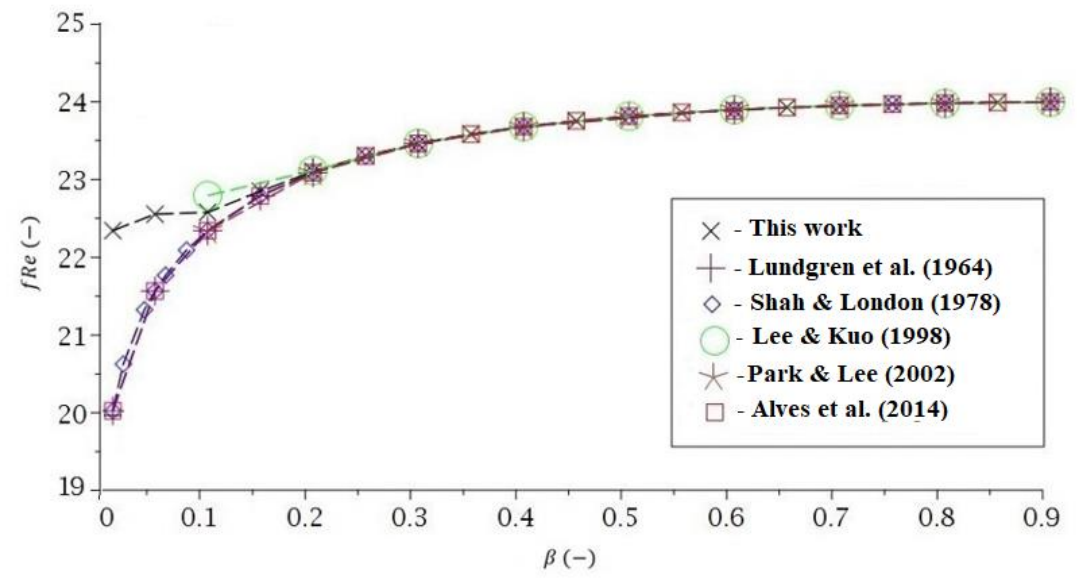

Source: Authors (2020).

Figure 6: Hagenbach factor for different aspect ratios compared to the literature data (G1 geometry).

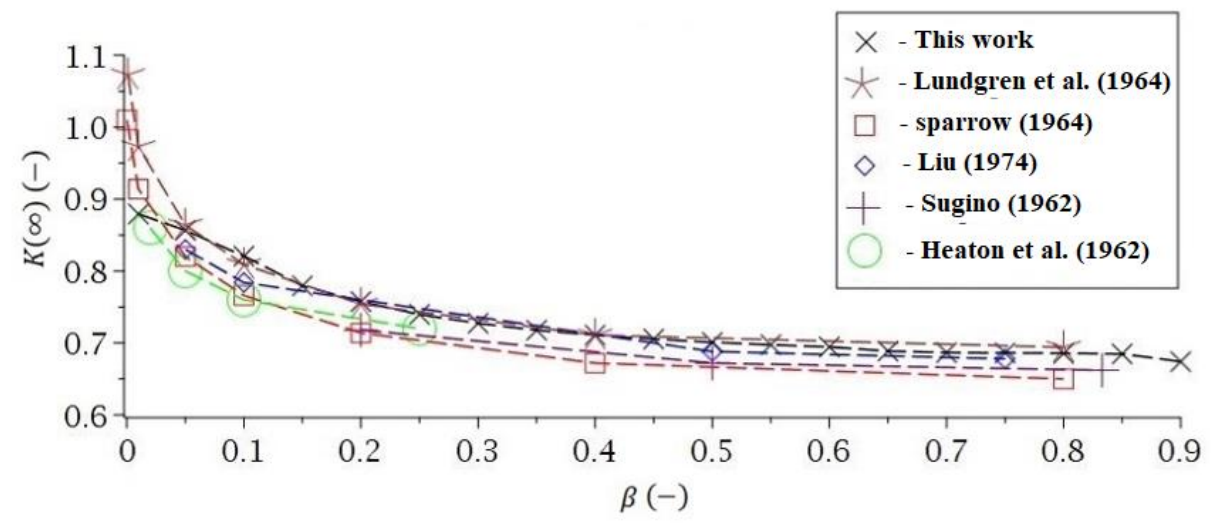

Source: Authors (2020). 
Figure 7: Dimensionless hydrodynamic entry length for different aspect ratios compared to the literature data (G1 geometry).

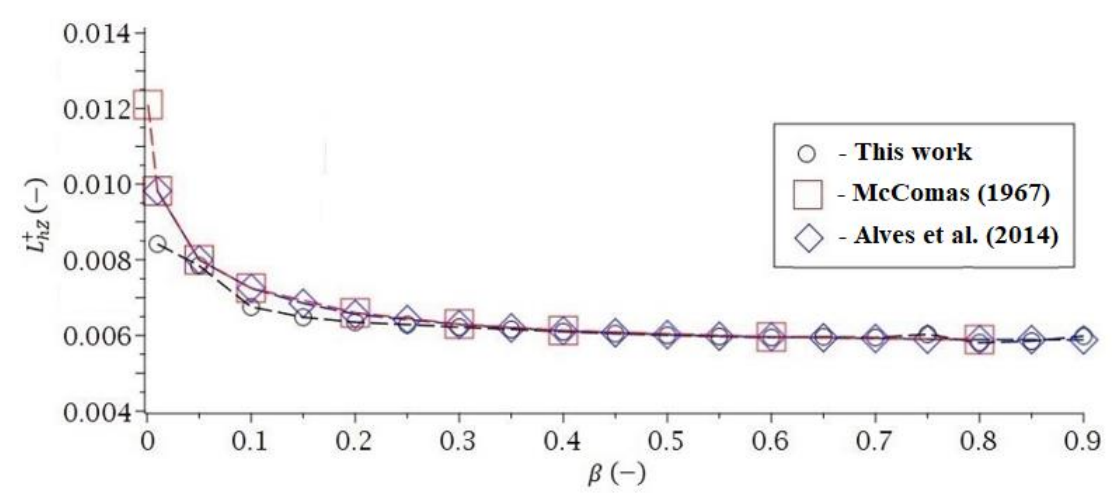

Source: Authors (2020).

It was observed a large computational effort in obtaining the hydrodynamic parameters when the aspect ratio is close to 0 and 1 .

\section{G2 Geometry}

For G2 geometry, Figure 2(b), two aspect ratios are considered: the first concerns to $c_{1}(\theta)$, with $\beta_{1}=\frac{p_{1}}{a_{1}}, a_{1}=1$, and $p_{1}=0.9,0.7$ and 0.5 ; the second concerns to the relationship between the curve $c_{2}(\theta)$ and $c_{1}(\theta)$, that is, $\beta=\frac{p_{2}}{p_{1}}$ and $a_{2}=p_{2}$ as the curve $c_{2}(\theta)$ is a circumference.

Figure 8, illustrates the velocity field of the fluid inside the duct. Similarly, to the concentric circular ducts, it is verified that velocity is null at both wall and increasing towards the central region of the annular. However, it can be observed nonsymmetrical values of the velocity. Since that body force does not has any effect in this parameter, it is exclusively due to differences in the thickness between the internal and external walls of the ducts. For small thickness values, lower velocity is obtained.

Also, it is notable that the fluid velocity is very sensitive to the shape of the duct. A peak of maximum velocity is clearly observed, and its magnitude is different for each geometry. The peak location in the cross-section of the duct varies accordingly with the established geometry. For G2 geometry, maximum and minimum velocities of 2.7116 and 0.2456 , respectively, were obtained. 
Figure 8: a) Geometrical profile, and b) Normalized dimensionless velocity profile for the G2 geometry. (surface curves: $a_{1}=$ $\left.1, p_{1}=0.7, a_{2}=p_{2}=0.56\right)$.

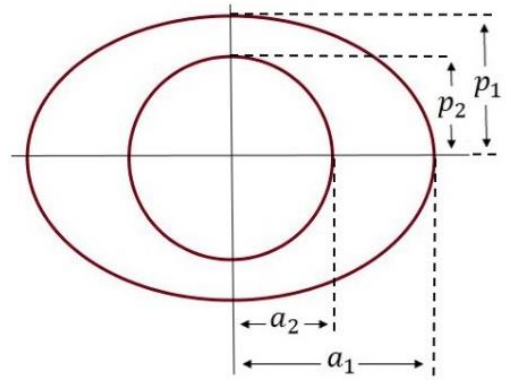

a)

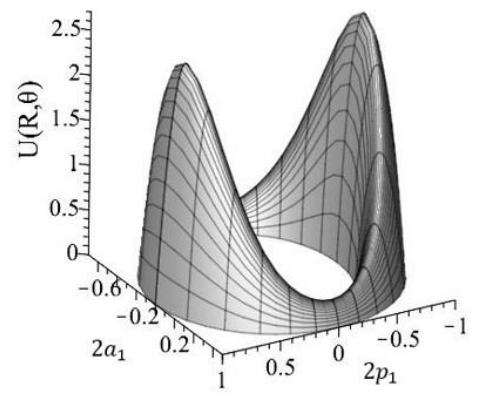

b)

Source: Authors (2020).

In Table 2, we present the values of the parameters obtained in the simulations.

Table 2: G2 geometry: Values of hydrodynamics parameters interest for G2 geometry.

\begin{tabular}{|c|c|c|c|c|c|c|c|}
\hline$\beta_{1}=\frac{p_{1}}{a_{1}}$ & $\beta=\frac{p_{2}}{p_{1}}$ & $f R e$ & $W_{m}$ & $U_{\max }$ & $K(\infty)$ & $L_{h z}^{+}$ & $D_{h}$ \\
\hline 0.90 & 0.50 & 23.5801 & 0.02103 & 1.8600 & 0.8628 & 0.01693 & 0.996 \\
\hline 0.90 & 0.55 & 23.5359 & 0.01706 & 1.8855 & 0.8914 & 0.01767 & 0.906 \\
\hline 0.90 & 0.60 & 23.4717 & 0.01419 & 1.9115 & 0.9235 & 0.01843 & 0.816 \\
\hline 0.90 & 0.66 & 23.3074 & 0.01040 & 1.9625 & 0.9940 & 0.01992 & 0.708 \\
\hline 0.90 & 0.70 & 23.1806 & 0.00874 & 1.9950 & 1.0465 & 0.02085 & 0.637 \\
\hline 0.90 & 0.80 & 22.4452 & 0.00464 & 2.1356 & 1.3216 & 0.02494 & 0.457 \\
\hline 0.90 & 0.90 & 20.1246 & 0.00190 & 2.3818 & 2.0044 & 0.03315 & 0.277 \\
\hline 0.90 & 0.95 & 16.8244 & 0.00112 & 2.4576 & - & - & 0.187 \\
\hline 0.70 & 0.50 & 22.4135 & 0.02043 & 2.5385 & 1.9374 & 0.03911 & 0.957 \\
\hline 0.70 & 0.60 & 21.2617 & 0.01582 & 2.5894 & 2.1806 & 0.04144 & 0.820 \\
\hline 0.70 & 0.70 & 19.6758 & 0.01185 & 2.6522 & 2.4930 & 0.04499 & 0.683 \\
\hline 0.70 & 0.80 & 17.3430 & 0.00857 & 2.7116 & 2.8409 & 0.05062 & 0.545 \\
\hline 0.70 & 0.90 & 13.7944 & 0.00602 & 2.7209 & 3.0495 & 0.06078 & 0.408 \\
\hline 0.50 & 0.50 & 22.4373 & 0.01636 & 3.1094 & 3.3835 & 0.05889 & 0.857 \\
\hline 0.50 & 0.60 & 20.0391 & 0.01462 & 3.0831 & 3.4993 & 0.06245 & 0.766 \\
\hline 0.50 & 0.70 & 17.5198 & 0.01294 & 3.0477 & 3.5839 & 0.06713 & 0.673 \\
\hline 0.50 & 0.80 & 14.7887 & 0.01104 & 2.1356 & 3.5816 & 0.06906 & 0.581 \\
\hline 0.50 & 0.90 & 11.8077 & 0.01006 & 2.8620 & - & - & 0.487 \\
\hline
\end{tabular}

Source: Authors (2020). 
By analyzing the results reported in Table 2, one can verify that the values of Poiseuille number and $W_{m}$ increase with a decreases in the parameters $\beta$, and meanwhile $U_{\max }, K(\infty)$ and $L_{h z}^{+}$have increased as $\beta$ increased. This behavior occurs for any fixed value of the $\beta_{1}$ aspect ratio. For the values shown in Table 2 , there were variations in the number of chosen base functions ranging from $N=3$ to $N=15$. We state that results and discussions with the same geometry are presented in previous works (Moharana \& Khandekar, 2013), when the behavior of the normalized dimensionless velocity profile is observed geometrically using other methodologies.

Figure 9-13 illustrate the behavior of the hydrodynamic parameter as a function of the $\beta$ parameter. Figures 9 and 10 show the results reported in Table 2, and some numerical values for $f R e$ found in the literature are used for comparison purpose. Analyzing the figures, we can see that a good agreement was except for the smaller parameter $\beta$, which can be attributed to the fact that a larger number of base functions, consequently a longer computational time, are necessary for the convergence of the values. This increase in base functions can significantly difficult the calculation of the inverse matrix $A^{-1}$ that makes up the matrixial system in Equation (18).

Figure 9: Poiseuille number for different aspect ratios compared to the literature data (G2 geometry, $\beta_{1}=0.9$ ).

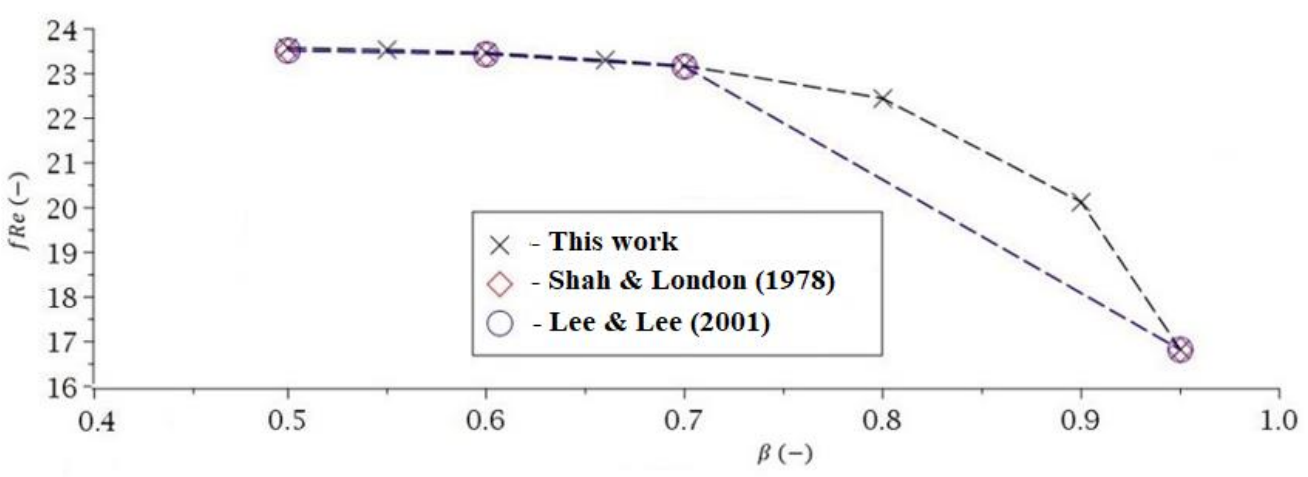

Source: Authors (2020).

Figure 10: Poiseuille number for different aspect ratios compared to the literature data ( $\mathrm{G} 2$ geometry, $\beta_{1}=0.7$ ).

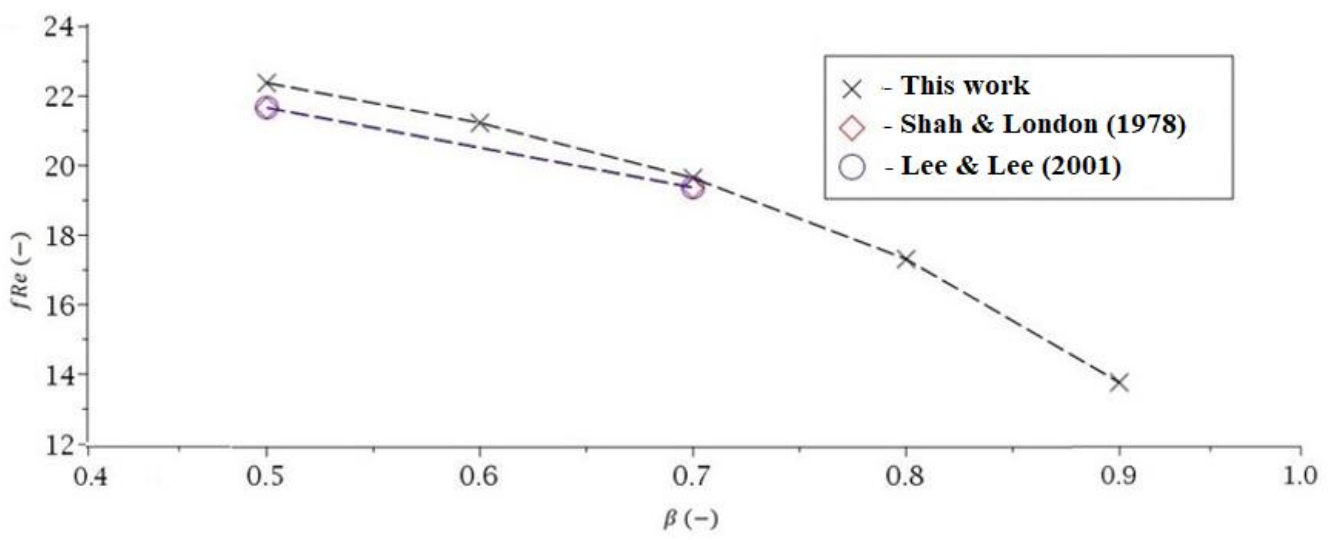

Source: Authors (2020). 
Research, Society and Development, v. 10, n. 1, e10710111547, 2021

(CC BY 4.0) | ISSN 2525-3409 | DOI: http://dx.doi.org/10.33448/rsd-v10i1.11547

Figure 11: Poiseuille number for different aspect ratios (G2 geometry, $\left.\beta_{1}=0.5\right)$.

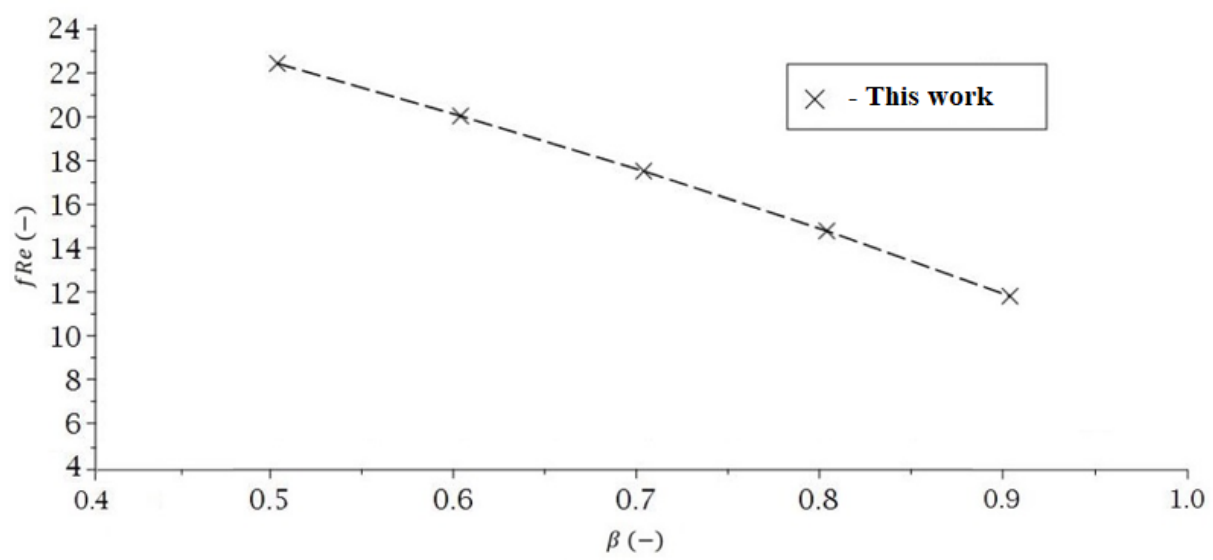

Source: Authors (2020).

In Figures 12 and 13, we present the graphs presented in Table 2 for the values of $K(\infty)$ and $L_{h z}^{+}$. From the analysis of these figures we can observe an increase in the parameters with increased $\beta$ parameter (fixed $\beta_{1}$ values) and decreasing with increased $\beta_{1}$ parameter (fixed $\beta$ values).

Figure 12: Hagenbach factor for different aspect ratios (G2 geometry).

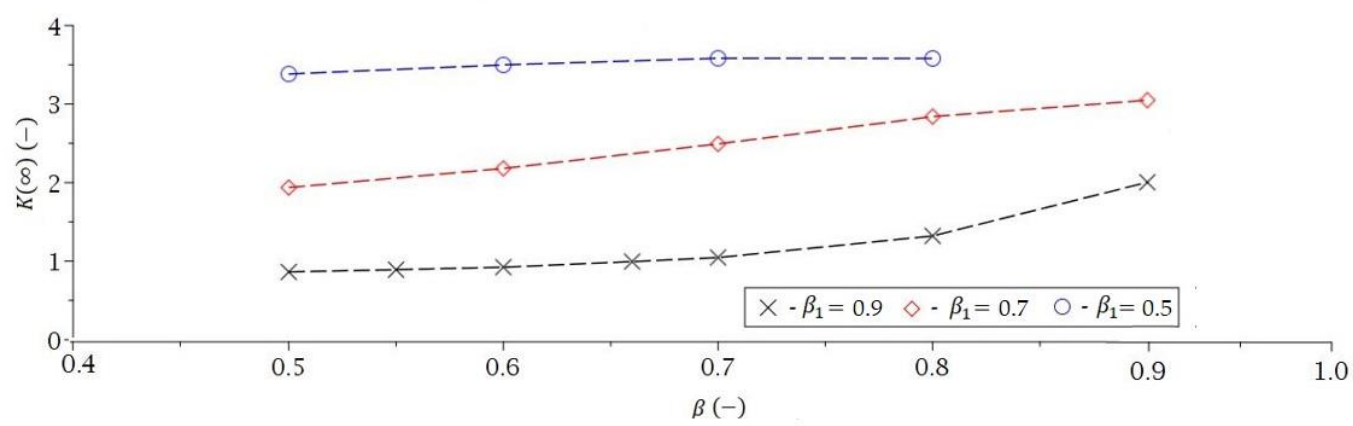

Source: Authors (2020).

Figure 13: Dimensionless hydrodynamic entry length for different aspect ratios (G2 geometry).

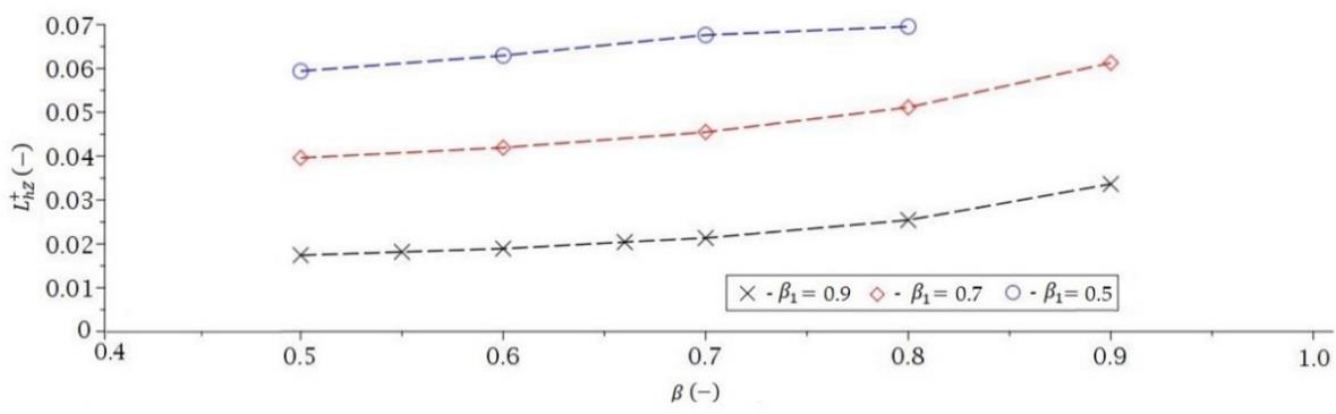

Source: Authors (2020). 


\section{G3 Geometry}

For the G3 geometry (Figure 2c), here we considered confocal ellipses, with two aspect ratios: the first concerns to $c_{1}(\theta)$, with $\beta_{1}=\frac{p_{1}}{a_{1}}, a_{1}=1$, and the second concerns to relationship between the curves $c_{2}(\theta)$ and $c_{1}(\theta)$, that is, $\beta=\frac{p_{2}}{p_{1}}$. Since that the ellipses are confocal, we have the following relationship $a_{1}^{2}-p_{1}^{2}=a_{2}^{2}-p_{2}^{2}$.

Figure 14 shows the velocity profile of the fluid in a cross-section area of the duct. From the analysis of this figure, we can see an almost similar behavior find to G2 geometry, however for this case smaller variations in the velocity with the angular coordinate are seen.

Figure 14: a) Geometrical profile, and b) Normalized dimensionless velocity profile for the G2 geometry (surface curve with $\beta_{1}=0.9$ and $\left.\beta=0.7\right)$.

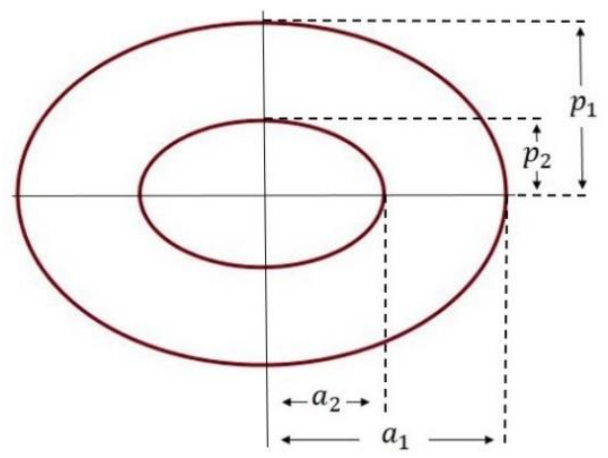

a)

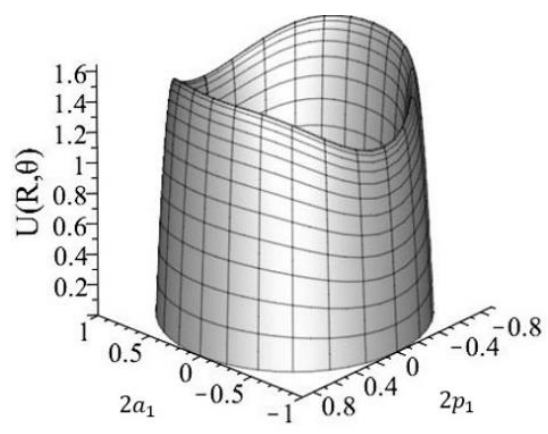

b)

Source: Authors (2020).

In Table 3, we present the values of the hydrodynamic parameters obtained in the simulations. By analyzing the results reported in Table 3, one can verify that the values of Poiseuille number, $U_{\max }$ and $L_{h z}^{+}$increase with the increased $\beta$ parameter, and meanwhile $W_{m}$ and $K(\infty)$, parameter have decreased as $\beta$ increased. This behavior occurs for any fixed value of the $\beta_{1}$ aspect ratio. However, for fixed value of the $\beta$ parameter, Poiseuille number and $W_{m}$ have increased as $\beta_{1}$ increased. 
Table 3. Several hydrodynamics parameters obtained for G3 geometry.

\begin{tabular}{cccccccc}
\hline $\boldsymbol{\beta}_{\mathbf{1}}=\frac{\boldsymbol{p}_{\mathbf{1}}}{\boldsymbol{a}_{\mathbf{1}}}$ & $\boldsymbol{\beta}=\frac{\boldsymbol{p}_{\mathbf{2}}}{\boldsymbol{p}_{\mathbf{1}}}$ & $\boldsymbol{f} \boldsymbol{R}$ & $\boldsymbol{W}_{\boldsymbol{m}}$ & $\boldsymbol{U}_{\max }$ & $\boldsymbol{K}(\infty)$ & $\boldsymbol{L}_{\boldsymbol{h} \boldsymbol{z}}^{+}$ & $\boldsymbol{D}_{\boldsymbol{h}}$ \\
\hline 0.90 & 0.20 & 24.392 & 0.032586 & 1.55539 & 0.88232 & 0.00550 & 1.261 \\
0.90 & 0.30 & 23.887 & 0.026584 & 1.60701 & 0.85939 & 0.00756 & 1.127 \\
0.90 & 0.40 & 23.769 & 0.020269 & 1.62507 & 0.82414 & 0.00859 & 0.982 \\
0.90 & 0.50 & 23.758 & 0.014435 & 1.62741 & 0.79043 & 0.00902 & 0.828 \\
0.90 & 0.60 & 23.830 & 0.009393 & 1.62460 & 0.77334 & 0.00908 & 0.669 \\
0.90 & 0.70 & 23.842 & 0.005364 & 1.61640 & 0.74713 & 0.00907 & 0.506 \\
0.90 & 0.80 & 23.868 & 0.002412 & 1.61275 & 0.73121 & 0.00910 & 0.339 \\
0.90 & 0.90 & 23.889 & 0.000609 & 1.61867 & - & - & 0.171 \\
0.80 & 0.40 & 23.697 & 0.014214 & 1.54402 & 0.92070 & 0.00488 & 0.821 \\
0.80 & 0.50 & 23.488 & 0.010243 & 1.59869 & 0.89533 & 0.00703 & 0.694 \\
0.80 & 0.60 & 23.445 & 0.006727 & 1.63581 & 0.87343 & 0.00855 & 0.562 \\
0.80 & 0.70 & 23.468 & 0.003860 & 1.66327 & 0.86236 & 0.00963 & 0.426 \\
0.80 & 0.80 & 23.525 & 0.001742 & 1.67559 & 0.84546 & 0.01022 & 0.286 \\
0.80 & 0.90 & 23.560 & 0.000442 & 1.69809 & - & - & 0.144 \\
\hline
\end{tabular}

Source: Authors (2020)

For the values presented in Table 3, we consider only few base functions $(N=3)$. This fact occurred because there are a very high computational efforts when considering a more significant number of base functions. Figures 15 and 16 illustrate a comparison between the results of the Poiseuille number as a function of the $\beta$ parameter, obtained in this research with the data reported in the literature. Despite of the use of small base functions number, we can see that a good concordance was obtained, except for the small $\beta$ parameter.

Figure 15: Poiseuille number for different aspect ratios compared to the literature data (G3 geometry, $\left.\beta_{1}=0.9\right)$.

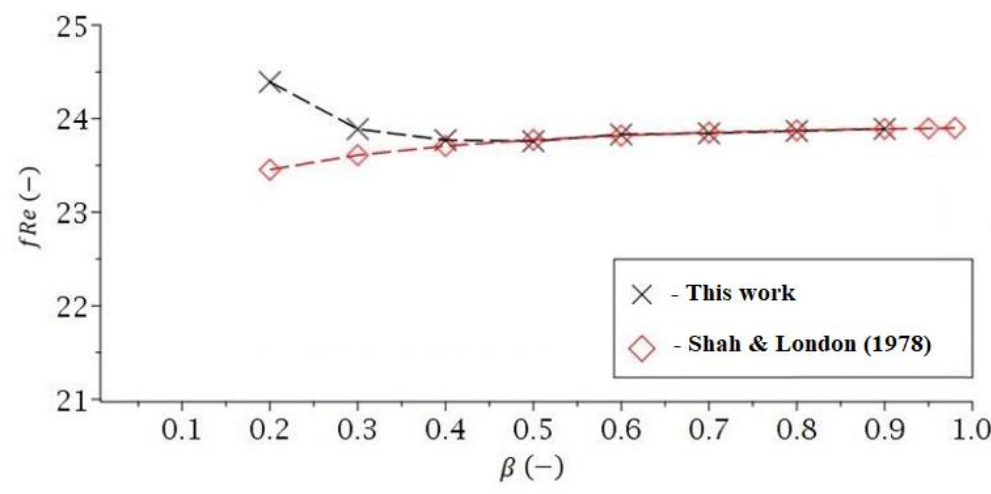

Source: Authors (2020). 
Figure 16: Poiseuille number for different aspect ratios compared to the literature data (G3 geometry, $\left.\beta_{1}=0.8\right)$.

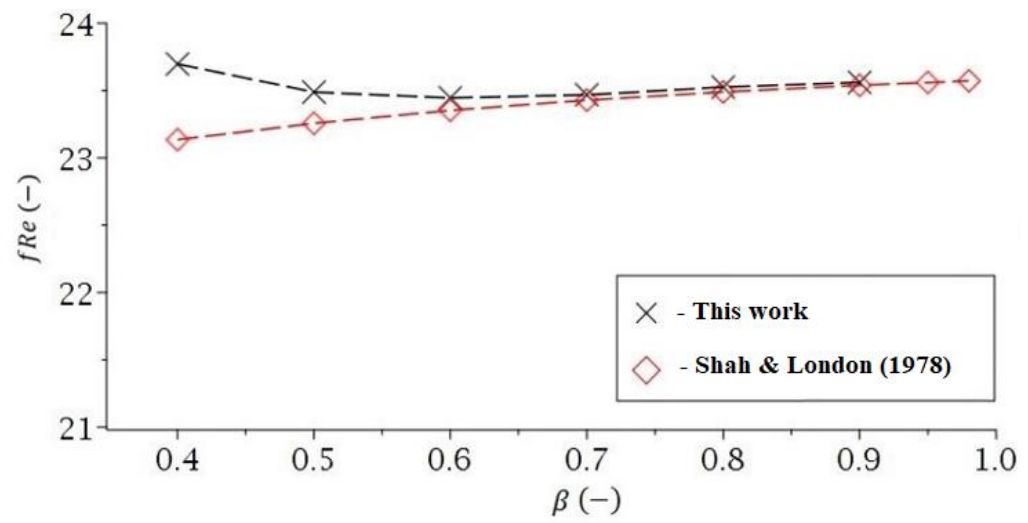

Source: Authors (2020).

In Figures 17 and 18, we present the parameters $K(\infty)$ and $L_{h Z}^{+}$as a function of the $\beta$ aspect ratio for two values of the $\beta_{1}$ parameters.

Figure 17: Hagenbach factor for different aspect ratios (G3 geometry).

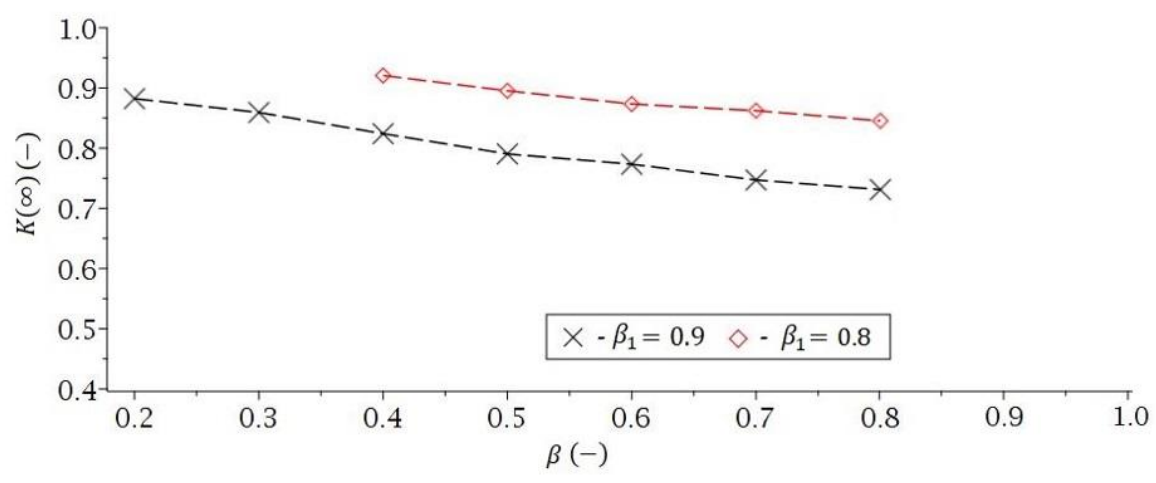

Source: Authors (2020).

Figure 18: Dimensionless hydrodynamic entry length for different aspect ratios (G3 geometry).

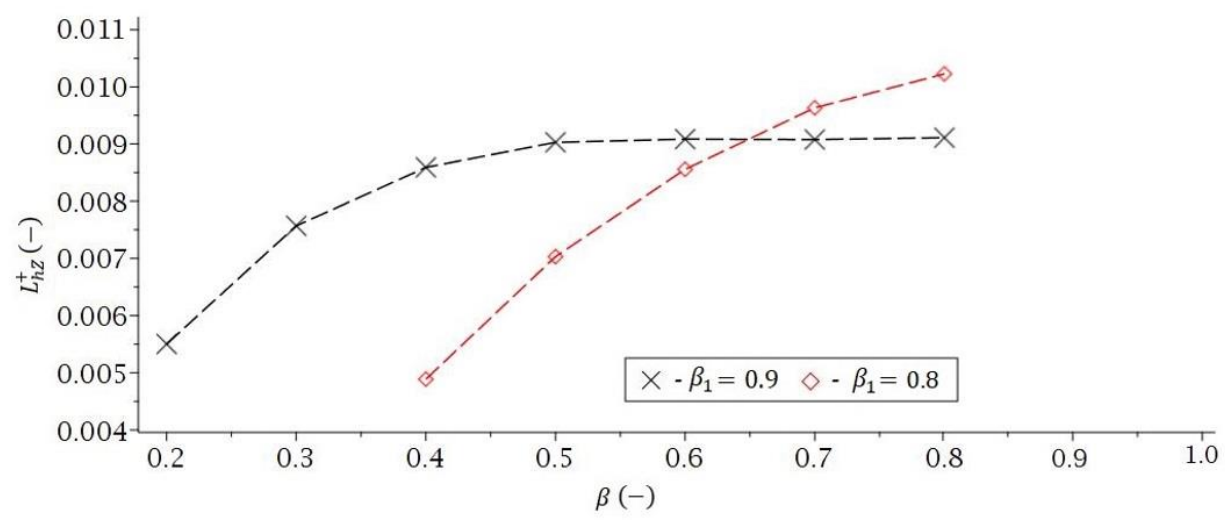

Source: Authors (2020). 


\section{G4 Geometry}

Now, we consider the G4 geometry, that corresponds to circumference with concentric elliptical core, Figure 2(d). The following aspect ratios were considered: the first concerns the relationship between the major axis of $c_{2}(\theta)$, with the radius of the circumference, that is, $\beta_{1}=\frac{a_{2}}{a_{1}}$, and the second concerns the relationship between the minor axis of $c_{2}(\theta)$, with the radius of the circumference, $\beta=\frac{p_{2}}{p_{1}}$. For convenience, here we consider $a_{1}=p_{1}=1$.

Figure 19 shows the dimensionless velocity profile inside the duct, for one specified geometrical condition. Similarly, to other cases, a peak of velocity is verified in the annular region. This behavior is in accordance with the reported data in the literature (Lima et al., 2004).

Figure 19: a) Geometrical profile, and b) Normalized dimensionless velocity profile for the G4 geometry (surface curves $\beta_{1}=0.6$ and $\left.\beta_{2}=0.3\right)$.

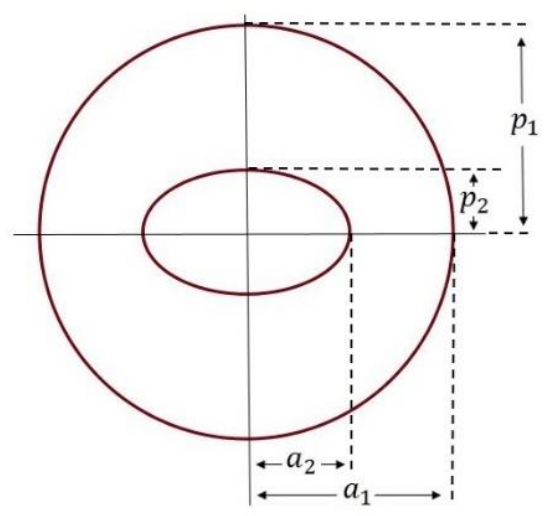

a)

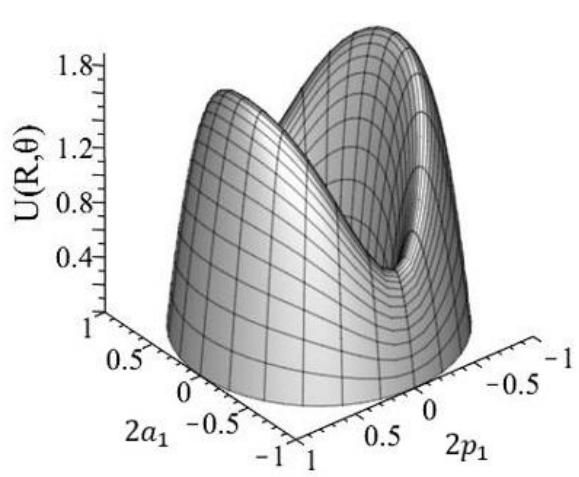

b)

Source: Authors (2020).

In Table 4, we present the values of the hydrodynamic parameters obtained in this research. From the analysis of this table, we can see that the Poiseuille number increase as $\beta$ is increased, for all fixed $\beta_{1}$ values. All the other parameters have an increase until to reach a maximum value, followed by decreasing. This behavior was verified for all $\beta_{1}$ fixed values. 
Research, Society and Development, v. 10, n. 1, e10710111547, 2021

(CC BY 4.0) | ISSN 2525-3409 | DOI: http://dx.doi.org/10.33448/rsd-v10i1.11547

Table 4. Several hydrodynamics parameters obtained for G4 geometry.

\begin{tabular}{|c|c|c|c|c|c|c|c|}
\hline$\beta_{1}=\frac{a_{2}}{a_{1}}$ & $\beta=\frac{p_{2}}{p_{1}}$ & $f R e$ & $W_{m}$ & $U_{\max }$ & $K(\infty)$ & $L_{h z}^{+}$ & $D_{h}$ \\
\hline 0.9 & 0.3 & 16.3018 & 0.024363 & 1.98597 & 1.3867 & 0.02388 & 0.891 \\
\hline 0.9 & 0.4 & 16.0168 & 0.018245 & 2.09858 & 1.6176 & 0.02788 & 0.764 \\
\hline 0.9 & 0.5 & 16.0768 & 0.012804 & 2.19436 & 1.8127 & 0.03113 & 0.642 \\
\hline 0.9 & 0.6 & 16.6246 & 0.008241 & 2.27267 & 1.9665 & 0.03306 & 0.523 \\
\hline 0.9 & 0.7 & 17.9548 & 0.004690 & 2.31469 & 2.0155 & 0.03261 & 0.410 \\
\hline 0.9 & 0.8 & 20.6846 & 0.002213 & 2.23048 & 1.6929 & 0.02758 & 0.303 \\
\hline 0.9 & 0.9 & 23.9944 & 0.000833 & 1.49502 & 0.6741 & 0.00598 & 0.200 \\
\hline 0.8 & 0.3 & 18.7918 & 0.024662 & 2.06623 & 1.4818 & 0.02378 & 0.963 \\
\hline 0.8 & 0.4 & 18.9238 & 0.018695 & 2.08257 & 1.5520 & 0.02358 & 0.841 \\
\hline 0.8 & 0.5 & 19.6460 & 0.013320 & 2.14977 & 1.6211 & 0.02545 & 0.723 \\
\hline 0.8 & 0.6 & 20.9174 & 0.008908 & 2.14194 & 1.5035 & 0.02491 & 0.610 \\
\hline 0.8 & 0.7 & 22.6973 & 0.005565 & 1.98422 & 1.1054 & 0.02017 & 0.503 \\
\hline 0.8 & 0.8 & 23.9801 & 0.003336 & 1.50088 & 0.6856 & 0.00580 & 0.400 \\
\hline 0.7 & 0.3 & 20.7968 & 0.025970 & 1.98231 & 1.3075 & 0.01949 & 1.039331089 \\
\hline 0.7 & 0.4 & 21.3015 & 0.019993 & 2.01823 & 1.3158 & 0.02062 & 0.9229137996 \\
\hline 0.7 & 0.5 & 22.2142 & 0.014781 & 1.99644 & 1.1877 & 0.02023 & 0.8103859308 \\
\hline 0.7 & 0.6 & 23.3011 & 0.010593 & 1.84910 & 0.9044 & 0.01625 & 0.7026206992 \\
\hline 0.7 & 0.7 & 23.9494 & 0.007515 & 1.50208 & 0.6865 & 0.00594 & 0.6000000004 \\
\hline 0.6 & 0.3 & 23.5162 & 0.017320 & 1.89147 & 1.0911 & 0.01668 & 1.121299034 \\
\hline 0.6 & 0.4 & 22.8433 & 0.022326 & 1.88514 & 1.0049 & 0.01695 & 1.009958304 \\
\hline 0.6 & 0.5 & 23.8970 & 0.013390 & 1.19098 & 0.8188 & - & 0.9025637604 \\
\hline 0.6 & 0.6 & 22.9691 & 0.037783 & 1.50429 & 0.6944 & 0.00594 & 0.8000000000 \\
\hline 0.5 & 0.2 & 23.1427 & 0.037783 & 1.79527 & 0.9549 & 0.01380 & 1.317460316 \\
\hline 0.5 & 0.3 & 23.5595 & 0.031572 & 1.79615 & 0.8971 & 0.01435 & 1.208867566 \\
\hline 0.5 & 0.4 & 23.5595 & 0.025791 & 1.25806 & 0.7790 & - & 1.102391528 \\
\hline 0.5 & 0.5 & 23.8127 & 0.020997 & 1.50713 & 0.6996 & 0.00600 & 1.000000000 \\
\hline
\end{tabular}

Source: Authors (2020).

For the values presented in Table 4, we consider nine base functions $(N=9)$. 
Figure 20: Poiseuille number for different aspect ratios (G4 geometry).

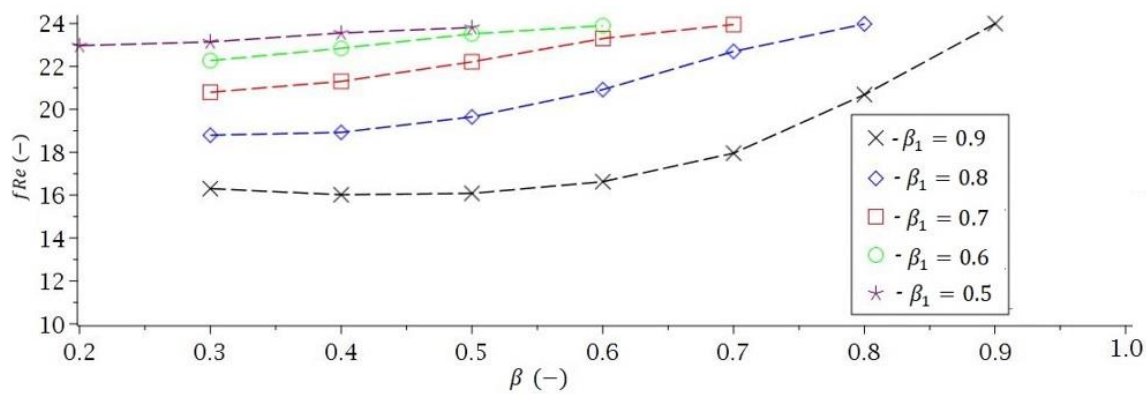

Source: Authors (2020).

Figure 21: Hagenbach factor for different aspect ratios (G4 geometry).

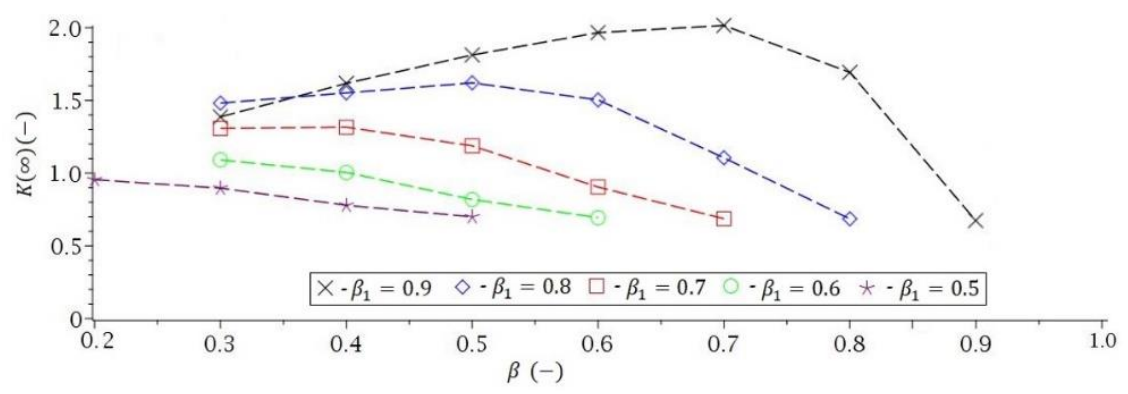

Source: Authors (2020).

Figure 22: Dimensionless hydrodynamic entry length for different aspect ratios (G4 geometry).

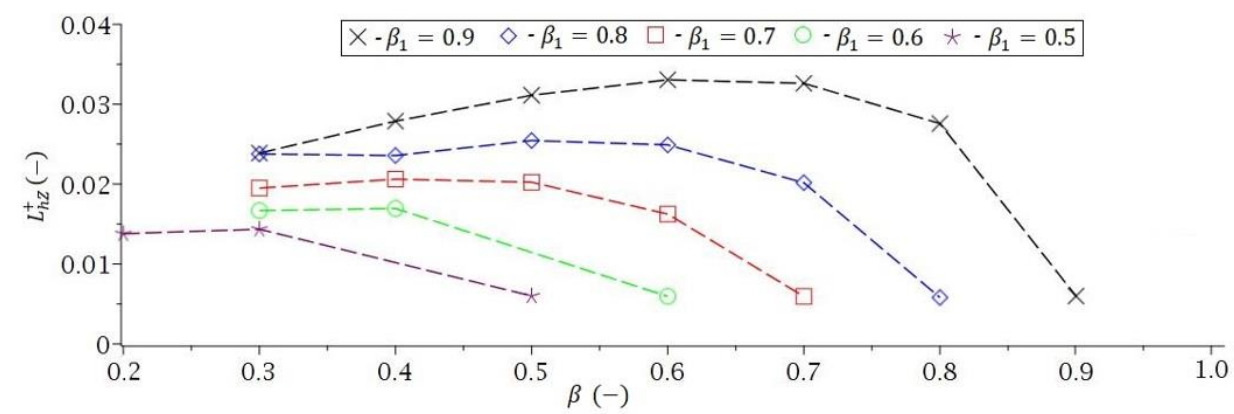

Source: Authors (2020).

Figures 20-22 illustrate the behavior of the hydrodynamic parameter as a function of the $\beta$ geometrical parameters, for several $\beta_{1}$ parameters. From the analysis of Figure 20, we can verify that an increase in the $\beta$ parameter provokes an increase in the Poiseuille number, for any fixed $\beta_{1}$ parameter. On the other hand, for the fixed value of the $\beta$ parameter, a reduction in the 
$\beta_{1}$ parameter provoked an increase in the $f R e$ hydrodynamic parameter. Furthermore, for lower $\beta_{1}$ value, the Poiseuille number has an almost linear behavior, and for higher $\beta_{1}$ value this parameter presents a minimum value for a specific $\beta$ value.

By analyzing Figure 21, we can state that the behavior of the Hagenbach factor is in contrast with the Poiseuille number, increasing as the $\beta_{1}$ parameter is increased, for a fixed $\beta$ value. Similar behavior was observed for the dimensionless hydrodynamic entry length.

Based on the results reported in Table 4 and Figure 20 we state that they are in accordance with the results reported in Table 1 (G1 geometry), as $\beta \rightarrow 1$, that is equivalent to the case as $\beta \rightarrow \beta_{1}$ and, thus, validating all procedures used in this research.

\section{Conclusions}

The Galerkin-based integral method in a two-dimensional approach is used for investigating the laminar flow fluid in doubly-connected ducts (circular with circular core, elliptical with circular core, elliptical with elliptical core, and circular with elliptical core). It is demonstrated that the velocity profile, Hagenbach factor, Poiseuille number, and fluid dynamic entry length, can be effectively predicted by this technique. The results, when compared with the literature data, showed good concordance, thus giving a robust applicability of the method and the parameterizations considered for the geometries studied here.

Depending on the duct geometry, aspect ratio, and the number of base functions considered, we have variations in computational effort and accuracy in the obtained results. The study showed that, especially for elliptical core geometries, to use a smaller number of base functions is more advantageous. For smaller aspect ratio, for example, $0<\beta<0.1$ and even $0<\beta<$ 0.4 , higher computational time and reduced accuracy were verified. Further, the obtained results show that the dimensionless velocity distribution presents a peak in the annular region which location is dependent on the duct shape (geometry and aspect ratio).

Finally, the GBI method may be used to predict fluid flow behavior in a duct of different shapes, in which solutions or available data do not exist.

In view of the applicability of the Galerkin-based integral method in unconventional geometries, the authors recommend to study fluid flow in duct of different geometries, in which solutions or available data do not exist, and in circular ducts with incrustations, which are originated of paraffin depositions in oil transportation, or solid particles in areas of basic sanitation.

\section{Acknowledgements}

The authors thank CNPq, Finep, and Capes (Brazilian Research Agencies) for financial support, and the authors of the cited references who helped in the improvement.

\section{Conflicts of Interest}

The authors declare no conflict of interest.

\section{References}

Alegria, L., Franco, A. T., Negrao, C., Morales, R., Martins, A. L., \& Waldmann, A. T. A. (2012, January). Friction factor correlation for viscoplastic fluid flows through eccentric elliptical annular pipe. In IADC/SPE Asia Pacific Drilling Technology Conference and Exhibition. Society of Petroleum Engineers.

Alves, T. A., Ramos, R. A. V., \& Maia, C. R. M. (2014). Escoamento laminar de fluidos Newtonianos em dutos anulares concêntricos. RECEN-Revista Ciências Exatas e Naturais, 16(2), 285-306. 
Cade, M. A., Lima, W. C. P. B., Neto, S. F., \& Lima, A. G. B. (2010). Natural gas laminar flow in elliptic cylindrical pipes: A numerical study. Brazilian Journal of petroleum and gas, $4(1)$.

Colmanetti, A. R. A. (2016). Estudo experimental de escoamento multifásico em duto anular de grande diâmetro (Doctoral dissertation, Universidade de São Paulo).

Das, S. K., \& Tahmouresi, F. (2016). Analytical solution of fully developed gaseous slip flow in elliptic microchannel. Int. J. Adv. Appl. Math. Mech, 3(3), 115 .

de Lima, A. B., Delgado, J. M. P. Q., Santos, I. B., Santos, J. S., Barbosa, E. S., \& e Silva, C. J. (2014). GBI Method: a powerful technique to study drying of complex shape solids. In Transport Phenomena and Drying of Solids and Particulate Materials (pp. 25-43). Springer, Cham.

de Oliveira Pinto, Y. L. (2016). Simuladores para o cálculo do fator de atrito para fluidos lei de potência em dutos circulares e anulares (Doctoral dissertation, Universidade Federal do Rio de Janeiro).

dos Santos, I. B., de Lucena Silva, L. P., \& de Lima, A. G. B. (2012). Mass transfer in irregularly-shaped solid: an exact solution using the galerkin-based integral method. In Defect and Diffusion Forum (Vol. 326, pp. 199-204). Trans Tech Publications Ltd.

dos Santos Júnior, V. A. (2018). Escoamento de fluido em dutos de seção arbitrária utilizando o método integral baseado em Galerkin. Estudo de caso: óleo pesado. (Tese de Doutorado em Engenharia de Processos) - Programa de Pós-Graduação em Engenharia de Processos, Centro de Ciências e Tecnologia, Universidade Federal de Campina Grande, Campina Grande, Brasil.

dos Santos Junior, V. A., de Farias Neto, S. R., de Lima, A. G. B., Gomes, I. F., Galvão, I. B., Franco, C. M. R., \& do Carmo, J. E. F. (2020). Heavy Oil Laminar Flow in Corrugated Ducts: A Numerical Study Using the Galerkin-Based Integral Method. Energies, 13(6), 1363.

Escudier, M. P., Gouldson, I. W., \& Jones, D. M. (1995). Flow of shear-thinning fluids in a concentric annulus. Experiments in Fluids, $18(4), 225-238$.

Etaig, S., \& Hashem, G. (2020). Numerical Investigation on the Laminar Flow in a Vertical Pipe with Elliptic Cross Section. International Journal of Science and Research (IJSR), 9, 1588-1592.

Ferroudji, H., Hadjadj, A., Haddad, A., \& Ofei, T. N. (2019). Numerical study of parameters affecting pressure drop of power-law fluid in horizontal annulus for laminar and turbulent flows. Journal of Petroleum Exploration and Production Technology, 9(4), 3091-3101.

Franco, C. M. R., Barbosa de Lima, A. G., Silva, J. V., \& Nunes, A. G. (2016). Applying liquid diffusion model for continuous drying of rough rice in fixed bed. In Defect and Diffusion Forum (Vol. 369, pp. 152-156). Trans Tech Publications Ltd.

Franco, C. M., de Lima, A. G., Farias, V. S., \& da Silva, W. P. (2020). Modeling and experimentation of continuous and intermittent drying of rough rice grains. Heat and Mass Transfer, 56(3), 1003-1014.

Franco, R., Barbosa de Lima, A. G., de Oliveira Farias, V. S., \& Machado, E. A. (2020). Intermittent Drying of Rice Grains with Husk: Modelling and Experimentation. In Diffusion Foundations (Vol. 25, pp. 9-36). Trans Tech Publications Ltd.

Gulraiz, S., \& Gray, K. E. (2020). Investigating the effects of plug viscosity on annular pressure drop and cuttings transport in a concentric annulus. Journal of Natural Gas Science and Engineering, 76, 103210.

Haji-Sheikh, A., \& Beck, J. V. (1990). Green's function partitioning in Galerkin-based integral solution of the diffusion equation. Journal Heat Transfer (Trans. ASME), 112, 28-34

Heaton, H. S., Reynolds, W. C., \& Kays, W. M. (1964). Heat transfer in annular passages. Simultaneous development of velocity and temperature fields in laminar flow. International Journal of Heat and Mass Transfer, 7(7), 763-781.

Khalil, M. F., Kassab, S. Z., Adam, I. G., \& Samaha, M. (2008, March). Laminar flow in concentric annulus with a moving core. In Twelfth Int. Water Technol. Conf. Alexandria, Egypt (pp. 439-457).

Lakshminarayanan, R., \& Haji-Sheikh, A. (1992). Entrance heat transfer in isosceles and right triangular ducts. Journal of thermophysics and heat transfer, 6(1), $167-171$.

Lasode, O. A., Popoola, T. O., \& Prasad, B. V. S. S. S. (2013). Numerical Study of Liquefied Petroleum Gas Laminar Flow in Cylindrical Elliptic Pipes. World Academy of Science-Engineering \& Technology, 7(6), 390-398.

Lee, Y. M., \& Kuo, Y. M. (1998). Laminar flow in annuli ducts with constant wall temperature. International communications in heat and mass transfer, 25(2), $227-236$.

Lee, Y. M., \& Lee, P. C. (2001). Laminar flow in elliptic ducts with and without central circular cores for constant wall temperature. International communications in heat and mass transfer, 28(8), 1115-1124.

Lekner, J. (2007). Viscous flow through pipes of various cross-sections. European journal of physics, $28(3), 521$.

Lima, D. R., Farias, S. N., \& Lima, A. G. B. (2004). Mass transport in spheroids using the Galerkin method. Brazilian journal of chemical engineering, 21(4), $667-680$.

Liu, Jim Sheau-Kung. (1974). Flow of a Bingham fluid in the entrance region of an annular tube. M.S. Thesis. University of Wisconsin-Milwaukee, Milwaukee, USA. 
Research, Society and Development, v. 10, n. 1, e10710111547, 2021

(CC BY 4.0) | ISSN 2525-3409 | DOI: http://dx.doi.org/10.33448/rsd-v10i1.11547

Lundgren, T. S., Sparrow, E. M., \& Starr, J. B. (1964). Pressure drop due to the entrance region in ducts of arbitrary cross section. Journal Basic Engineering, 86,620 .

McComas, S. T. (1967). Hydrodynamic entrance lengths for ducts of arbitrary cross section. Journal Basic Engineering. 89, 847-856.

Moharana, M. K., \& Khandekar, S. (2013). Generalized formulation for estimating pressure drop in fully-developed laminar flow in singly and doubly connected channels of non-circular cross-sections. Computer Methods in Applied Mechanics and Engineering, 259, 64-76.

Moharana, M. K., \& Khandekar, S. (2013). Generalized formulation for estimating pressure drop in fully-developed laminar flow in singly and doubly connected channels of non-circular cross-sections. Computer Methods in Applied Mechanics and Engineering, 259, 64-76.

Muzychka, Y. S., \& Yovanovich, M. M. (2009). Pressure drop in laminar developing flow in noncircular ducts: A scaling and modeling approach. Journal of Fluids Engineering, 131(11).

Nouar, C., Ouldrouis, M., Salem, A., \& Legrand, J. (1995). Developing laminar flow in the entrance region of annuli-Review and extension of standard resolution methods for the hydrodynamic problem. International journal of engineering science, 33(10), 1517-1534.

Park, S., \& Lee, D. R. (2002). Predictions of pressure drop for modified power law fluids in conduits of three different cross-sectional shapes. Chemical engineering science, 57(6), 1057-1067.

Pereira A. S., Shitsuka, D. M., Parreira, F. J., Shitsuka, R. (2018). Metodologia da pesquisa científica. Editora UAB/NTE/UFSM, Santa Maria/RS. Recuperado de https://repositorio.ufsm.br/bitstream/handle/1/15824/Lic_Computacao_MetodologiaPesquisa Cientifica.pdf?sequence=1.

Pessôa, P. M., Barbosa de Lima, A. G., Swarnakar, R., Gomes, J. P., \& de Lima, W. M. (2016). Cooling of Fruit with Arbitrary Shape: Simulation Using Galerkin-Based Integral Method. In Diffusion Foundations (Vol. 10, pp. 1-15). Trans Tech Publications Ltd.

Santos, J. P. S., Santos, I. B., Pereira, E. M. A., Silva, J. V., \& de Lima, A. G. B. (2015). Wheat convective drying: An analytical investigation via galerkinbased integral method. In Defect and Diffusion Forum (Vol. 365, pp. 82-87). Trans Tech Publications Ltd.

Shah, R. K., \& London, A. L. (2014). Laminar flow forced convection in ducts: a source book for compact heat exchanger analytical data. Academic press.

Shivakumar, P. N., \& Ji, C. (1993). On the Poisson's Equation for Doubly Connected Regions. Canadian Appl. Math. Quarterly, 1, 555-568.

Solanki, S. C., Saini, J. S., \& Gupta, C. P. (1986). Flow through doubly connected ducts. International journal of heat and fluid flow, 7(4), 301-306.

Sparrow, E. M., \& Lin, S. H. (1964). The developing laminar flow and pressure drop in the entrance region of annular ducts.

Sugino, E. (1962). Velocity distribution and pressure drop in the laminar inlet of a pipe with annular space. Bulletin of JSME, 5(20), 651-655.

Uner, D., Ozgen, C., \& Tosun, I. (1988). An approximate solution for non-Newtonian flow in eccentric annuli. Industrial \& engineering chemistry research, 27(4), 698-701.

Velusamy, K., \& Garg, V. K. (1993). Entrance flow in elliptical ducts. International journal for numerical methods in fluids, $17(12)$, 1079-1096.

\section{List of Symbols}

$\begin{array}{ll}a_{i}, p_{i} & \text { Geometric dimensions, major and minor axes of the ellipse, }(\mathrm{m}) \\ a_{i j} & \text { Element of matrix } A \\ A_{c} & \text { Cross-section area of the duct, }\left(\mathrm{m}^{2}\right) \\ A^{-1} & \text { Inverse matrix of } A \\ A, B, D, \chi, E, \Psi, \bar{P} & \text { Matrix } \\ b_{j}, b_{i j} & \text { Element of matrix } B \text { (constants) } \\ C_{1}, C_{2} & \text { Parameterizations of the curves } \\ d_{h} & \text { Hydraulic diameter, (m) } \\ d_{j}, d_{n j} & \text { Constants to be evaluated, } \\ D_{h} & \text { Dimensionless hydraulic diameter } \\ f & \text { Fanning friction factor, (dimensionless) }\end{array}$


$f_{i}$

fRe

$g$

$K(\infty)$

$K_{e}(\infty)$

$K_{d}(\infty)$

$L$

$L_{h Z}^{+}$

$N$

$P$

$p$

$r, \theta, z$

Re

$u$

$u_{m}$

$U$

$U_{\max }$

W

$W_{m}$

$W_{\max }$

$\beta, \beta_{i}$

$\mu$

$\tau_{w}$

$\psi_{i}$

$\Gamma$

$\nabla^{2}$

$\frac{d p}{d z}$
Base functions; Galerkin Functions

Poiseuille number, (dimensionless)

Parameterization function

Hagenbach factor, (dimensionless)

Kinetic energy factor

Momentum flow correction factor

Characteristic length, (m)

Dimensionless fluid-dynamic input length, (dimensionless)

Number of base functions

Perimeter, (m)

Pressure, $(\mathrm{Pa})$

Cylindrical coordinates

Reynolds number, (dimensionless)

Local axial velocity, $(\mathrm{m} / \mathrm{s})$

Mean velocity, $(\mathrm{m} / \mathrm{s})$

Normalized velocity, (dimensionless)

Maximum dimensionless velocity, (dimensionless)

Dimensionless velocity, (dimensionless)

Dimensionless mean velocity, (dimensionless)

Maximum value of dimensionless velocity, (dimensionless)

Aspect ratios, (dimensionless)

Dynamic Viscosity, $(\mathrm{Pa} \cdot \mathrm{s})$

Shear stress, $(\mathrm{Pa})$

Element of the matrix $\Psi$

Boundary of duct

Laplacian operator

Pressure gradient, $(\mathrm{Pa} / \mathrm{m})$ 